\title{
Health Related Quality of Life among Patients with Ischaemic Heart Disease in Kano, Nigeria
}

\section{Mijinyawa MS1, Yusuf SM1', Gambo $\mathrm{MI}^{2}$, Saidu $\mathrm{H}^{3}$ and Dalhatu $\mathrm{A}^{4 *}$}

${ }^{1}$ Department of Medicine, Bayero University Kano and Aminu Kano Teaching Hospital, Kano, Nigeria

${ }^{2}$ Department of Nursing, Aminu Kano Teaching Hospital, Nigeria

${ }^{3}$ Department of Medicine, Bayero University Kano and Murtala Muhammad Specialist Hospital, Kano, Nigeria

${ }^{4}$ Department of Nursing Sciences, Bayero University Kano, Nigeria

\begin{abstract}
The study examined the quality of life of patients with Ishaemic Heart Diseases (IHD). IHD has been projected to be one of the primary causes of disability and morbidity in many developing countries around the globe. The disease is therefore a vital indicator of patient morbidity and long term disability. It is associated with significant physical, emotional, social and cognitive consequences and contributes greatly to escalating cost of health care. A cross-sectional study design was employed, and a purposive sampling technique was used to recruit the total sample size of eighty. The data was obtained using a standardized data collection form of Short Form Health Survey (SF-36). The data was analyzed using SPSS version 16 . The study revealed that $(63.7 \%)$ of the subjects were between the age group of $61-80$ years, and $47.5 \%$ had no western education. The study showed that hypertensive disorders, depressive ailments and history of cigarette smoking were the major contributing factors to poor quality of life. The study concluded that there is an overwhelming limited quality of life in patients with IHD. Therefore, it is recommended that health education, non pharmacological programs, and improvement in the health care sector is needed to achieve promising results.
\end{abstract}

Keywords: Patient; Health; Quality of life; Ischaemic heart disease

\section{Background}

Ischaemic heart disease affects and kills an increasingly large number of people [1]. It is a diagnosis characterized by increased mortality rates and hospitalizations as well as poor quality of life [2]. It is already the leading cause of deaths in men and the second leading cause of deaths in women in the African region [3]. The World Health Organization [WHO] estimated that in 2005, IHD caused approximately 361,000 deaths in the African region, and current projections suggest that this number will nearly double by 2030 . More recent projections of mortality and burden of disease suggest that by 2030, IHD will become the leading cause of death in low income countries, contributing $13.4 \%$ of total deaths, versus $13.2 \%$ from HIV/AIDS and other chronic diseases [4]. In addition, IHD is projected to rank fifth among the 10 leading causes of disability-adjusted life years [DALYs] in low-income countries by 2030 [5].

The epidemiological transition provides a useful framework for understanding the rise of ishaemic heart disease in low income countries (such as most African, South American and Asian countries). Previous reports [5], state that the epidemiological transition posits that populations initially start with low life expectancies with mortality primarily driven by infections, under nutrition, and illnesses and injuries related to childbirth. As sanitation, education and agriculture improve, these causes of death gradually recede until Non Communicable Diseases [NCD], particularly IHD and cancers, dominate the causes of low quality of life and death [6]. Later, as cancers and IHD becomes preventable or controllable, the burden of these diseases became unbearable to the patients' quality of life. Some researchers [7] suggested that in light of recent adverse trends in physical activity, diet, ageing, and obesity have led to the epidemiological transition and reduced quality of life of patients with ischaemic heart disease. There has also been a dramatic rise in several IHD risk factors that affect client's quality of life, which is attributed to poor compliance to treatment, incapacitation and reoccurrence of angina pain [8]. Ischaemic heart disease is one of the primary causes of disability and morbidity in many developed countries as well as some developing countries around the globe [9]. Patients with ischaemic heart disease may live with a chronic illness that may subjects to poor quality of life that may cause further cardiac damage and death $[9,10]$. The World Health Organization estimated that in 2005, ischaemic heart diseases caused approximately 361,000 deaths in the African region, and current projections suggest that this number will nearly double by $2030[9,10]$.

\section{Methodology}

\section{Study design}

A descriptive, cross-sectional design was employed for the study.

\section{Study setting}

The study setting was at Murtala Muhammed Specialist Hospital (MMSH), Kano, Nigeria. It is located in the historical city of Kano. It has a capacity of 688 beds and serves as a referral centre for the state with a projected population of 15 million people.

\section{Target population}

The total number of eighty (80) subjects with a diagnosis of ischaemic heart disease were recruited. These subjects were serially recruited from the cardiac clinic as well as from the male and female medical wards of the hospital after obtaining an informed consent.

*Corresponding author: Dalhatu A, Department of Nursing Sciences, Bayero University Kano, Nigeria, Tel: +234 909439 6848; E-mail: adamudalhatu206@gmail.com

Received July 25, 2016; Accepted August 08, 2016; Published August 16, 2016

Citation: Mijinyawa MS, Yusuf SM, Gambo MI, Saidu H, Dalhatu A (2016) Health Related Quality of Life among Patients with Ischaemic Heart Disease in Kano, Nigeria. J Vasc Med Surg 4: 282. doi: 10.4172/2329-6925.1000282

Copyright: (C) 2016 Mijinyawa MS, et al. This is an open-access article distributed under the terms of the Creative Commons Attribution License, which permits unrestricted use, distribution, and reproduction in any medium, provided the original author and source are credited. 


\section{Research instrument}

"WHO Quality of Life-BREF (WHOQOLBREF), SF-36 (Short Form Health Survey) questionnaire" was the adopted questionnaire that was used to obtain information from the respondents. The value of the SF-36 has been previously compared with that of other generic questionnaires in patients with CHD. Some studies have concluded that the SF-36 is the most appropriate generic instrument to assess the Quality Of Life (QOL) of cardiac patients. The questionnaire is divided into three sections, with section A composing of socio-demographic data such as: sex; age; marital status; religion; place of residence; level of education; occupation; habit; financial support system, type of family; number of support persons; primary cause of patients' Ischaemic heart disease; co-morbidity that accompanied the Ishaemic heart disease. While section B is on SF-36 Survey, which comprises of: general health; limitations of activities; physical health problems; emotional health problems; social activities; pain; energy and emotion. Section $\mathrm{C}$ is on Family support information.

\section{Methods of data collection}

The data were collected by the researchers and trained research assistant. The questionnaire were administered to the respondents and interpreted verbally to their language of understanding.

\section{Data Analysis}

The obtained data were inputted into a SPSS (Statistical Package for Social Sciences) software V.16, and analyzed using descriptive (frequency distributions and percentages using tables)

\section{Results}

In Table 1, it shows that there were 51 males and 29 females in the study, giving a male to female ratio of 1:7:1. Majority of the respondents (63.7\%) were aged 61-80 years and a near similar percentage were married. Over forty-seven percent (47.5\%) had no western education, while only $(3.8 \%)$ had tertiary education. Most of the subjects were urban dwellers (80\%).

In Table 2 it shows over forty-seven percent (47.5\%) have history of hypertension, this is followed by history of smoking (18.8\%). Then diabetes mellitus with $13.8 \%$, with small proportion of $12.5 \%$ having obesity.

In Table 3 it shows over forty-one percent (41.25\%) of respondent's general health were fair and, small proportion (11.25\%) were of poor health.

In Table 4, it shows over sixty-two percent (62.5\%) of respondents were much limited in vigorous activities, small proportion $(2.5 \%)$ of respondents were not limited in vigorous activities. Over sixty two (62.5\%) percent of respondents were partly limited in a moderate activities and over $48 \%$ of respondents were depressed.

\section{Discussion}

Most of the respondents in this study were males (63.7\%). The male predominance is similar to the observations in other studies [11]. The median age of subjects in this study is 70 years, similar demographic observation was reported from other parts of the world [12]. This study also found that most of the subjects lacked western education and were elderly. Chambless and his colleagues [13] reported similar demographic observation in their study. The reason for this can be explained by the fact that ischaemic heart diseases mainly affect older people, perhaps due to the increase in prevalence of hypertension and

\begin{tabular}{|c|c|c|}
\hline Variable $\mathbf{N}=\mathbf{8 0}$ & Frequency & Percentage \\
\hline \multicolumn{3}{|l|}{ Gender: } \\
\hline Male & 51 & 63.7 \\
\hline Female & 29 & 36.3 \\
\hline Total & 80 & 100 \\
\hline \multicolumn{3}{|l|}{ Marital status: } \\
\hline Single & 5 & 6.2 \\
\hline Married & 51 & 63.7 \\
\hline Divorced & 13 & 16.3 \\
\hline Widow & 11 & 13.8 \\
\hline Total & 80 & 100 \\
\hline \multicolumn{3}{|l|}{ Age(years) } \\
\hline $20-40$ & 10 & 12.5 \\
\hline $41-60$ & 15 & 18.7 \\
\hline $61-80$ & 51 & 63.8 \\
\hline $81-100$ & 4 & 5 \\
\hline Total & 80 & 100 \\
\hline \multicolumn{3}{|l|}{ Religion: } \\
\hline Islam & 72 & 90 \\
\hline Christianity & 8 & 10 \\
\hline Total & 80 & 100 \\
\hline \multicolumn{3}{|l|}{ Place of residence: } \\
\hline Urban & 64 & 80 \\
\hline Rural & 16 & 20 \\
\hline Total & 80 & 100 \\
\hline Level of education: & & 47.5 \\
\hline No formal education & 38 & 47.5 \\
\hline Primary & 37 & 46.3 \\
\hline Secondary & 2 & 2.5 \\
\hline Tertiary & 3 & 3.8 \\
\hline Total & 80 & 100 \\
\hline \multicolumn{3}{|l|}{ Occupation: } \\
\hline Unemployed & 18 & 22.5 \\
\hline Government & 8 & 10 \\
\hline Private & 40 & 50 \\
\hline Retired & 14 & 17.5 \\
\hline Total & 80 & 100 \\
\hline \multicolumn{3}{|l|}{ Type of family: } \\
\hline Monogamy & 12 & 15 \\
\hline Polygamy & 68 & 85 \\
\hline Total & 80 & 100 \\
\hline
\end{tabular}

Table 1: Socio-demographic characteristics of the respondents.

\begin{tabular}{|c|c|c|}
\hline Variable N=80 & Frequency & Percentage \\
\hline Primary factors: & & \\
\hline Hypertension & 38 & 47.5 \\
\hline Diabetes mellitus & 11 & 13.8 \\
\hline Obesity & 10 & 12.5 \\
\hline Familial history & 6 & 7.5 \\
\hline Cigarette smoking & 15 & 18.8 \\
\hline Total & 80 & 100 \\
\hline
\end{tabular}

Table 2: Associated factors related to respondents' condition.

diabetes in the elderly. Lack of western education can predispose an individual to poor healthy life style which may have remote negative impact on the heart and blood vessels.

The result of the present study show that high blood pressure, cigarette smoking and depression had adverse effect on the quality 
Citation: Mijinyawa MS, Yusuf SM, Gambo MI, Saidu H, Dalhatu A (2016) Health Related Quality of Life among Patients with Ischaemic Heart Disease in Kano, Nigeria. J Vasc Med Surg 4: 282. doi: 10.4172/2329-6925.1000282

Page 3 of 4

\begin{tabular}{|c|c|c|}
\hline Variable $\mathbf{N}=\mathbf{8 0}$ & Frequency & Percentage \\
\hline \multicolumn{3}{|l|}{ How is your health now? } \\
\hline Excellent & 9 & 11.3 \\
\hline Very good & 12 & 15 \\
\hline Good & 16 & 20 \\
\hline Fair & 33 & 41.3 \\
\hline Poor & 10 & 12.5 \\
\hline Total & 80 & 100 \\
\hline \multicolumn{3}{|c|}{ How was your health few days back? } \\
\hline Much better & 9 & 11.3 \\
\hline Somewhat better & 36 & 45 \\
\hline About the same & 23 & 28.7 \\
\hline Somewhat worse & 10 & 12.5 \\
\hline Much worse & 2 & 2.5 \\
\hline Total & 80 & 100 \\
\hline
\end{tabular}

Table 3: Respondents' health related factors.

\begin{tabular}{|c|c|c|}
\hline Variable $\mathbf{N}=\mathbf{8 0}$ & Frequency & Percentage \\
\hline \multicolumn{3}{|l|}{ Engaging in vigorous activities: } \\
\hline Limited a lot & 50 & 62.5 \\
\hline Limited a little & 28 & 35 \\
\hline Not limited & 2 & 2.5 \\
\hline Total & 80 & 100 \\
\hline \multicolumn{3}{|l|}{ Engaging in moderate activities: } \\
\hline Limited a lot & 18 & 22.5 \\
\hline Limited a little & 50 & 62.5 \\
\hline Not limited & 12 & 15 \\
\hline Total & 80 & 100 \\
\hline \multicolumn{3}{|l|}{ Carrying light objects: } \\
\hline Limited a lot & 10 & 12.5 \\
\hline Limited a little & 22 & 27.5 \\
\hline Not limited & 48 & 60 \\
\hline Total & 80 & 100 \\
\hline Climbing several flight of stairs: & 55 & 68.8 \\
\hline Limited a lot & 25 & 31.3 \\
\hline Limited a little & 0 & 0 \\
\hline Not limited & 80 & 100 \\
\hline \multicolumn{3}{|l|}{ Total } \\
\hline Climbing one flight of stair: & 9 & 11.3 \\
\hline Limited a lot & 46 & 57.5 \\
\hline Limited a little & 25 & 31.3 \\
\hline Not limited & 80 & 100 \\
\hline \multicolumn{3}{|l|}{ Total } \\
\hline Bending, kneeling or stooping & 0 & 0 \\
\hline Limited a lot & 42 & 52.5 \\
\hline Limited a little & 38 & 47.5 \\
\hline Not limited & 80 & 100 \\
\hline Total & & 87.5 \\
\hline Walking more than a mile & 70 & 12.5 \\
\hline Limited a lot & 10 & 0 \\
\hline Limited a little & 0 & 100 \\
\hline Not limited & 80 & \\
\hline \multicolumn{3}{|l|}{ Total } \\
\hline :Bathing or dressing: & 12 & 15 \\
\hline Limited a lot & 50 & 62.5 \\
\hline Limited a little & 18 & 22.5 \\
\hline Not limited & 80 & 100 \\
\hline Total & & \\
\hline
\end{tabular}

\begin{tabular}{|c|c|c|}
\hline Walking one block & 16 & 20 \\
\hline Limited a lot & 40 & 50 \\
\hline Limited a little & 24 & 30 \\
\hline Not limited & 80 & 100 \\
\hline Total & & \\
\hline Walking several blocks: & 52 & 65 \\
\hline Limited a lot & 25 & 31.3 \\
\hline Limited a little & 3 & 3.8 \\
\hline Not limited & 80 & 100 \\
\hline Total & & 48.75 \\
\hline Do you feel depressed & 39 & 18.75 \\
\hline All of the time & 15 & 32.5 \\
\hline Most of the time & 26 & 100 \\
\hline None & 80 & \\
\hline Total & & \\
\hline Table Respondents limiting & & \\
\hline
\end{tabular}

Table 4: Respondents limiting factors to quality of life.

of life in individuals with IHD. In another study, the quality of life of patients with IHD was found to be associated with some modifiable factors such as smoking, depressive symptoms and angina pectoris [14]. The findings are also similar to reports from Malaysia in which it was reported that the quality of life of patients with IHD was associated with some demographic and clinical factors [15]. The apparent negative effect of smoking has a theoretical assertion; as smoking decreases oxygenation and also cause vasoconstriction there by increasing the cardiac stress.

However, this study found some demographic factors that did not have negative effect on health related quality of life such as gender, advancing age and low educational level. A different study reported by some researchers [15] observed that young age was associated with better quality of life. This is not surprising as old age is accompanied by problems of mobility, metabolism, decreased immunity and psychologic problems. Studies from other countries [16] reported that the quality of life of patients with IHD may be improved from time of admission up to 12 months after discharge.

\section{Conclusion}

Majority of the subjects have moderate to severe limitation of physical activity and presence of hypertension, cigarette smoking and depressive ailments in patients with ischaemic heart disease are associated with limitation of quality of life.

\section{References}

1. Center for Disease Control and Prevention (2010) Heat failure Fact sheet/CVH

2. Adams K, Lindenfield J, Arnold J, Massie B, Baker D, et al. (2006) Executive Summary: HFSA 2006 Comprehensive Coronary Heart disease Guidelines. Journal of Cardiac Failure 12: 10-38

3. Go AS, Mozaffarian D, Roger VL, Benjamin EJ, Berry JD, et al. (2013) Heart Disease and Stroke Statistics - 2013 Update: a report from the American Heart Association. Circulation 127: e6-e245.

4. Bosworth H, Steinhauser K, Orr M, Lindquist J, Grambow S, et al. (2005) Coronary Heart disease patients' perceptions of quality of life: the integration of physical and psychological factors. Aging \& Mental Health 8: 83-91.

5. Carels R (2005) The association between disease severity, functional status depression and daily quality of life in coronary heart disease patients. Quality of life Research 13: 63-72.

6. Kodiath M, Kelly A, Shively M (2005) Improving quality of life in patients with coronary heart disease: An innovative behavioral intervention. Journal of Cardiovascular Nursing 20: 43-48.

7. Konstam V, Salem D, Pouler H (2006) SOLVD Investigators. Baseline quality of 
Citation: Mijinyawa MS, Yusuf SM, Gambo MI, Saidu H, Dalhatu A (2016) Health Related Quality of Life among Patients with Ischaemic Heart Disease in Kano, Nigeria. J Vasc Med Surg 4: 282. doi: 10.4172/2329-6925.1000282

life as a predictor of mortality and hospitalization in patients with coronary heart disease. The American Journal of Cardiology 78: 890-895.

8. Ekman I, Fagerberg B, Lundman B (2008) Health-related quality of life and sense of coherence among elderly patients with severe coronary heart disease in comparison with healthy controls. Heart \& Lung 31: 94-101.

9. World Health Organization (2010) Cardiovascular diseases (CVDs).

10. Clark DO, Tu W, Weiner M, Murray M (2009) Correlates of healthrelated Quality of life among lower-income, urban adults with coronary heart disease. Heart \& Lung 32: 391-401.

11. Chambless, Coresh, Folsom, Heiss, Rosmond (2012) Facts on coronary heart disease 40: 220-410.
12. Malik H, Afzal N (2015) Predictors of quality of life and resilience among outpatients with heart diseases. Esp Cardiol 3: 31-33.

13. Azmi S, Goh A, Fong A, Anchah L (2015) Quality of life among patients with Acute Coronary Syndrum in Malaysia. Health Regional Issue pp: 80-83.

14. Rancic N, Kocic B, Mirko I (2015) The influence of angina pectoris on the quality of life of patients one month and twelve month after myocardial infarction. CDC: 616-618.

15. Staniute M, Vaskelyte J, Rumbinaite E, Kaminskaite B, Samsanavicene S, et al. (2005) Impact of left ventricular function on health-related quality of life in coronary artery disease patients. Medicana pp: 233-239.

16. Diass CC, Mateus $P$, Santos $L$ (2005) Acute coronary syndromes and predictors of quality of life. Revista Portuguese de cardiolagia pp: 819-831. 